\title{
CONSIDERACIONES CRÍTICAS SOBRE EL SISTEMA DE REFERENCIAS BIBLIOGRÁFICAS CONOCIDO POR SU SIGLAS EN INGLÉS COMO APA
}

Aníbal Alemán y Freddy Quezada

\begin{abstract}
Resumen:
En este ensayo se pretende iniciar un debate sobre un tema poco discutido por la comunidad universitaria, pero de gran presencia en el quehacer académico: el papel que juega en distintos momentos de la formación del estudiante y en los procesos de investigación del docente, el sistema de referencias bibliográfica conocida como APA. Las ideas expuestas en este trabajo, buscan poner en evidencia la naturaleza y el rol de un modelo de referencia surgido en academias del norte, y asumida sin mucha crítica por las instituciones latinoamericanas. Pero fundamentalmente, se reflexiona acerca de lo que está detrás de la imposición de las normas APA, la necesidad de controlar la representación de las autorías individuales, puesta en cuestión por la ampliación, hasta límites insospechados hasta hace unas décadas, de la circulación de la información, mensajes, textos, a través de una diversidad de medios o fuentes al alcance de la mayoría de la población.
\end{abstract}

Palabras claves: APA, Referencias bibliográficas, representación, circulación de información, medios de comunicación,

\begin{abstract}
:
This essay aims to start a debate upon a subject that has been shortly discussed within university community, but of great presence into academic environment: role reference and citation system known as APA style plays in different time to student education, and in process of teacher's research. Ideas set in this paper, aims to highlight nature and roll of a reference system that coming from north academy, which has been assumed without much criticism by Latin American institutions. However critical analysis is done upon what stands behind of APA rules, as the necessity to control individual author representation, questioned by flow of information, messages and texts, through different media or source, of unsuspected limits until few decades ago.
\end{abstract}

Keywords: APA style, references and citation system, mass media.

\section{Introducción}

La lectura del presente ensayo en esta revista, probará que no fue rechazado para su consideración, a pesar del empleo de unas reglas bibliográficas contraindicadas y que, de atribuirle un carácter excepcional a su publicación, será de recibo agradecer a su Consejo Editorial. Será, también de suyo, la prueba que existen otros modos de citar autores, a la espera de un dictamen experticio que certifique su invalidez y superación que, en nuestra investigación, nosotros no logramos encontrar.

El presente artículo nace de las angustias observada que pasan muchos estudiantes a la hora de utilizar referencias bibliográficas, para soportar la solidez de sus trabajos investigativos de curso $y$ las distintas 
modalidades de defensas de grado, donde su mal empleo se penaliza, a veces de manera desproporcionada.

En la UNAN-Managua, y en muchas universidades del país, así como en Centros de Investigaciones Regionales, Instituciones de Estudios Superiores y Revistas indexadas de América Latina, se usa el sistema de referencias bibliográficas conocidas por sus siglas en inglés llamada APA (American Psychological Association) cuyo manual de procedimientos cuenta con seis ediciones oficiales (http://www.cifcomlatinoamerica. com/Presentacion_Estilo_APA_6ta_Edicion. pdf $)^{1}$

En este escrito, por razones demostrativas, usaremos el estilo como prueba y no para citar, por esa razón se utilizará el anterior (a base de numeraciones sucesivas en superíndices dentro del cuerpo del texto y cuyas referencias bibliográficas, se presentarán al final, para no interrumpir la lectura, dejando a discreción del lector continuar o informarse de ellas al pie de página ${ }^{2}$ ), conocido como sistema de Vancouver $^{3}$ y así demostrar, por la vía del ejemplo, su pertinencia, recordando que no sólo existe el APA como modelo hoy dominante, sino otros, cuya validez y eficacia nadie ha concluido, por medio de un dictamen de colegio de expertos, hasta hoy, como improcedentes e inútiles.
En muchas universidades de Nicaragua, se ha establecido que un trabajo para ser calificado como científico debe utilizar las normas APA como sistema de referencias bibliográficas. Se ha llegado incluso a llamar, por algunos miembros de la comunidad académica, al empleo de unas reglas imperativas como indicador científico, confundiendo los medios con los resultados. Sin embargo, no sólo este sistema existe. Y aún más, cualquier sistema de referencias hunde sus raíces en el problema de la representación que se hacen unos pensadores con, y de, otros y todos ellos con respecto a sus objetos, sean naturales (a los que los científicos suponen mudos) o sociales, a los que los pensadores, por sí y ante sí, a través de macro conceptos, deciden representar sin su concurso. Entre Boyle y Hobbes. ${ }^{4}$

Todo intelectual, por principio, establece en gran parte su autoridad, en una cadena hermenéutica, a través de referencias de otras autoridades, que considera mayores y trascendentes, para criticarlas o servirse de ellas. El problema de un intelectual que cita a otro, es un fenómeno que no sólo cae dentro de la teoría de la representación, que veremos a continuación, sino de las interpretaciones y significados por parte de los receptores, que veremos al final. $Y$ este es el nudo que une esta explicación ensayística, a la espera de indagaciones más empíricas, de lo que representa el APA en términos epistémicos y la severidad con que se invita a obedecerlo.

1 Consiste en lo esencial en citar, in media res, referencias por medio del apellido de los autores, con la fecha entre paréntesis de las obras aludidas y la página exacta si la cita es textual. Al final, se dispone la bibliografía por orden alfabético. Las diferencias entre las últimas ediciones son muy pequeñas (ver https://es.scribd.com/doc/169507715/APA-Diferencias-5ta-y-6ta-Ediciones), en lo que respecta al núcleo duro del formato propiamente dicho, por ejemplo, los títulos de las obras, en la sexta edición, ya no necesitan presentarse en cursivas. La parte gruesa de las diferencias, corre a cuenta de ajustar el canon a las formas electrónicas de citar, muchas veces prescindiendo de apellidos y cuya presentación, a través de esos largos y alambicados códigos del protocolo html, rompen la belleza y economía que sus creadores creen haber logrado. Véase cuadro sinóptico más abajo.

2 En el APA se interrumpe la lectura en el seno de las obras, con apellidos, como cuando se ve una película en televisión abierta que, constantemente, rompe la atención y coherencia con anuncios publicitarios. Mientras que el sistema inglés, más gentil, se recoge en notas al pie, como esta misma, brindando la opción al lector de leerla o seguir de corrido la lectura en la parte superior.

3 En Europa, una parte significativa de académicos de renombre, véase Peter Sloterdijk, en Alemania, Rector de la Universidad de Karlsruhe (Cfr. Ira y Tiempo. Estacao Libertade. Sao Paulo, 2012), Zygmunt Bauman (Cfr. La cultura como praxis. Paidós. Barcelona, 2002 ) en Inglaterra y Slavoj Zizek (Viviendo el final de los tiempos. Akal. Madrid, 2010) en Francia y Argentina, entre otros, citados sólo porque son la moda hoy en América Latina, vivos y laureados, continúan usando el sistema inglés y, en algunas universidades estadounidenses, como Harvard, se permite una combinación flexible.

4 Bruno Latour ha trabajado este asunto. Ver su obra Nunca fuimos modernos. Siglo XXI. Bs. As. 2007. Sin embargo, no llegó tan lejos, pese a ser desprendible de su estudio, como para proponer la penalización de las promesas, por parte de los políticos y la de los pronósticos, por parte de los científicos. 


\section{El APA como parte de un problema de representación}

La representación epistémica moderna fue definida $\mathrm{y}$, al mismo tiempo criticado, por Heidegger. Decía más o menos que era la adecuación (exadaequatio) entre un sujeto y un objeto, fórmula que habría sido fundada por Kant, quien la presentó por vez primera como su "revolución copernicana". Pero Heidegger, yendo más allá, observó que tal atributo haría de todas las cosas un "objeto para un sujeto" que, sin advertirlo, haría del sujeto mismo, también, otro objeto más, concluyendo que jamás llegaremos a ser un sujeto ${ }^{5}$ y arrastrando todo, a un mundo de manipulaciones y cálculos, donde permanecería prisionera la metafísica, la ciencia y la técnica, descendientes unas de otras. $^{6} \mathrm{Y}$ todas, olvidando a un ser que se movería entre ellas, abriéndose a su posibilidad más auténtica (como lo planteó en Ser y Tiempo) y, ya en sus obras tardías, simplemente sucediéndose en los acontecimientos cotidianos, mediante una especie de apropiación disolvente (ereignis) y un darse (es gibt) gratuito, dejando ser al Ser. Quizás no sea tan claro en qué medida una representación calculadora, puede beneficiar a los intelectuales que la emplean, al decidirse por programas emancipadores, necesitados de sujetos sufrientes que soporten el esquema y se les reconozca como autoridad en los dos sentidos, como autores y como líderes.

Gayatri Spivak ${ }^{7}$, una pensadora india, y en la línea de su maestro Jacques Derrida, a su vez tributario de Heidegger, parece ser más clara, al establecer dos tipos de representaciones que, en alemán, cuenta con dos términos: vertretung y darstellung. El primer término es "hablar por alguien", lo que hacen, por lo general, los intelectuales al hablar por los subalternos; y el darstellung, que se ocupa mucho en el arte y que es hablar "como si fuera otro", lo que se conoce como representación escénica o imaginación literaria. Esto ha sido un recurso intelectual de toda la vida, porque siempre los pensadores han hablado por unos subalternos que existen de manera empírica, pero que ellos construyen, cargándolos casi siempre de virtudes especiales, hasta el grado de conseguir borrarse ellos mismos durante el acto. Entonces se presentan transparentes y proyectan la impresión que invitan a una voz "otra" a que hable, como si fuera autónoma. ${ }^{8}$ Este asunto, en sí mismo crucial para la interpretación que tenemos sobre la hegemonía del APA, no puede ser abordado aquí por razones de espacio. Pero sí podemos articularlo, dentro de la misma línea, de lo que hicieron algunos antropólogos estadounidenses, durante la embriaguez postmoderna que sufrieron muchas disciplinas entre las décadas de los ‘80 y un poco más del año 2000.

El APA no sólo son alertas tempranas, expresables en nuevas reglas para devolver la autoestima a unos autores deprimidos, sino la respuesta a la crisis provocada por ellos mismos, a partir del giro postmoderno de reconocer el debilitamiento de la autoridad (despotismo del emisor) en todos los sentidos,

5 Este es el principio que heredará Derrida, para establecer la diferancia, que consistirá en pasar de un significante a otro y de este a otro más y así sucesivamente sin alcanzar nunca la presencia o el significado pleno (Ousia). Tal registro lo llevó a expresar esa fórmula que lo hizo célebre: "no hay nada fuera del lenguaje".

6 En este contexto es donde Heidegger expresa que la "ciencia no piensa, calcula".

7 Gayatri Spivak. "¿Puede hablar el sujeto subalterno?” en Orbis Tertius. Año 3. No. 6. Universidad de La Plata. Argentina, 1998.

8 En realidad, en tal construcción, lo que hay es una cadena binaria que, desde Sócrates, voz narrativa de Platón, nos han hecho creer que ellos, los sabios y los sofistas, manejan la episteme, como Platón y Aristóteles, y otros, la retórica, como los sofistas. Tanto estos como aquellos, se unen en medio de sus diferencias, a veces violentas entre el saber y el poder, en contra de los que Sócrates llamó los "diez mil necios" de Atenas, conformados por hombre, mujeres, niños, atenienses, que cuentan sólo con una doxa, es decir, que ellos solamente pueden opinar, pero no pueden formular teorías ni saberes. (Cfr Bruno Latour. La Esperanza de Pandora. Gedisa. Barcelona, 2001, en especial la parte "Sócrates y Calicles contra el pueblo de Atenas", págs: 262-281). Se puede afirmar que lo que inaugura la relación y ese juego eurocéntrico de una categoría despreciable y oculta determinada por otra, maestra y brillante, se muestra entre la doxa de los atenienses necios y la episteme prestigiada y privilegiada de Platón y Sócrates, funcional a todo el juego binario, desde entonces, entre plebeyos romanos y patricios, siervos y sus señores, pecadores y sus pastores, burgueses y obreros, hasta desembocar en subalternos y hegemónicos y en una categoría muy especial, la de "ciudadano", que sólo crecerá en círculos expansivos y concéntricos a costa de sí misma. 
incluyendo el epistémico. En particular fue Stephen Tyler, y un grupo de autores denominados a sí mismos antropólogos posmodernos, quienes originaron el registro de la amenaza a la estabilidad de todo el sistema representacional de autores, al exigir créditos editoriales y derechos, al menos de coautoría, para los grupos étnicos que estudiaban como "objetos". Tyler alborotó el avispero.

El rehúso de reconocer la coautoría de los "objetos" de estudio, desencadenó lo que después pasó a conocerse como la "contrarrevolución copernicana" que no era más que la insubordinación de los actores sociales, construidos por los intelectuales desde sus programas emancipadores. Aún en el desorden de su retirada, para la caída del Muro de Berlín y la desintegración de la URSS, algunos pensadores mantuvieron una especie de guerrilla, que terminaron por reducir luces mesiánicas a sus sujetos sufrientes $y$, sin embargo, por otro lado, mantenerles privilegios epistémicos a algunos movimientos sociales. El caso de los decoloniales es ilustrador.

El intelectual empezó a resentir su papel representacional con la entrada de los medios de comunicación de masas, en donde se desplazó todo el acento de los emisores ilustrados a los usuarios, a la doxa, que es ahora la que reacciona desde esas pestañas interactivas en las redes sociales y desde donde se permite expresar groserías e insultos, es cierto, pero también opiniones muy elaboradas y donde ya no se distingue quién es el letrado simple y quién el doctor, por la disponibilidad del mismo banco de archivos electrónicos para todos.
La sacralidad del intelectual, empezó a debilitarse, pues, y llevar a algunos de ellos, a reconocer su rebajamiento y humillación de jueces de la humanidad a vulgares intérpretes, como nos confiesa Zygmunt Bauman. ${ }^{9}$ Los intelectuales en la actualidad son facilitadores porque, a su despecho, se obligan a saberse "otros" diferentes y sentirse, al mismo tiempo, igual que los demás. Han sufrido un golpe que le viene de deslegitimar su capacidad representativa en nombres de valores abstractos, sin lugares ni historias.

Para colmo, la carga interpretativa de los intelectuales ha llegado donde ya está siendo distribuida entre los receptores, por medio de los nuevos medios de comunicación interactivos. Ahora, recién ingresados al reino de la recepción, paso facilitado por la hermenéutica de los textos, se abre a la recuperación de una dignidad de las personas comunes y corrientes, que pueden tener acceso electrónico a unas redes desde las que ejercen, al menos, un poder reactivo. ${ }^{10}$ Es muy difícil en nuestros días que, por ejemplo, un paciente acepte la declaración pasivamente, por parte de su médico, de una dolencia severa acompañada de la respectiva medicación, si luego, para la siguiente cita, tal paciente no lleva ya varias preguntas y alternativas de curación, tomadas de Google.

\section{APA como problema de antropólogos}

Los antropólogos postmodernos estadounidenses, hemos dicho más arriba, cuestionaron la autoría de sus obras elaboradas sobre sus objetos de estudios, que eran algunas "tribus" no occidentales. Stephen Tyler ${ }^{11}$, el más radical de todos ellos,

9 Zygmunt Bauman. Legisladores e intérpretes. Ed. Quilmes. Argentina, 1997

10 La misma tecnología se encargará de proporcionar herramientas para ejercer más este poder en la red. Un ejemplo es la creación de una Internet tan rápida como la luz. Nos referimos a la tecnología LIFE (fidelidad Lumínica, por sus siglas en inglés), que podría ser una realidad comercial en octubre de este año. Se trata de una tecnología que utiliza la luz eléctrica para la transmisión de datos a una velocidad cinco veces superior a la del WIFI. La tecnología LIFE se considera todavía en fase experimental, debido al corto tiempo que tiene en desarrollo. En el año 2010, el físico alemán Harald Haas empezó a desarrollar esta tecnología en la universidad de Edimburgo en el Reino Unido y México será el primer país de América Latina que usará este tipo de tecnología por medio de la empresa Sisoft.

11 Stephen Tyler, antropólogo norteamericano, dice todas estas cosas en una antología de varios autores. C. Geertz, J Cliffor et al. El surgimiento de la Antropología Postmoderna, Gedisa, Barcelona, 1991.Véase el capítulo propiamente de Tyler "Acerca de la 'descripción/ desescritura' como un 'hablar por'; págs: 289-294 
creía que las obras de los antropólogos no eran propias, sino, al menos parcialmente, de los grupos étnicos estudiados. Tyler, decía que no podía ser posible que una historia étnica llevara el nombre de quien había efectuado un papel parecido al de un editor de historias ajenas.

Stephen Tyler y su escuela, amenazó todo el sistema de referencias por autor, que la antropología venía de compartir con los psicólogos estadounidenses del APA desde que se fundó tal régimen citacional, usado casi como ghetto por ellos, y toda la estima atesorada por los intelectuales, a base del reflejo de sus apellidos en el seno de unos textos ya amenazados por la teoría finita del receptor, ${ }^{12}$ atravesó un nerviosismo a la que habría que sumarle la epistémica, que pasaba de la tiranía del emisor a la polisemia de los receptores.

Tyler pues, concentra él solo los dos frentes de batalla abiertos con su crítica: por un lado, la decisión de los psicólogos de devolver la confianza a los autores por medio de la masificación de su particular método de referencias, ya sin la compañía de los antropólogos que, más o menos para la misma época, estaban por el otro lado, criticando epistémicamente a sus propios autores. En tal marco es donde se une una cosa con otra.
Los antropólogos gringos, pues, activaron algo que parecía más bien una denuncia y que se regó como pólvora en las demás disciplinas, al grado que los intelectuales no podían permanecer impunes, sin recibir un castigo al menos, o una censura de los "objetos", que en el caso de ellos, grupos étnicos no occidentales, no podían reclamar derechos de autor, ni protestar por múltiples razones.

Mientras esta tormenta tomaba lugar, muchas universidades y países continuaron usando el sistema inglés, el clásico. Este sistema proviene de la sociedad médica de Gran Bretaña y fue promovida por editores de sus revistas. Una conjetura altamente probable es que las diferencias entre psicólogos y médicos anglosajones, pueda provenir de rivalidades de mercados, usuarios, consumidores y financiamiento de proyectos científicos y el efecto que podría originar la sobre presencia o no, de autores en promoción abierta. Sospecha que de ser cierta, vista desde las Universidades del Sur, sería la triste confirmación de una esclavitud epistémica practicada por unas instituciones subalternas que en puridad, deberían resistirla, sobre todo aquellas que dicen combatir todo tipo de enajenación y obediencia ciega a centros imperiales de decisiones externas.

12 Ver Umberto Eco. Los límites de la interpretación. Ed. Lumen. Barcelona, 1992.

13 El problema por su magnitud, (y el peso del número puede aquí cambiar las perspectivas, invirtiendo los términos y siendo los censuradores los llamados a cambiar de actitud) como se sabe, está dejando de ser un asunto ético y se está volviendo un problema epistémico, porque es tan masivo el plagio de los textos electrónicos (a través del copy and paste), que, a su vez, muy posiblemente, estos son plagiados y así retroactivamente, de tal manera que se amenaza con declarar que no hay originales sólo copias de copias, un poco como Nietzsche decía de la realidad: "no hay hechos, sólo interpretaciones". 
DIFERENCIAS ENTRE SISTEMAS DE REFERENCIAS BIBLIOGRÁFICAS

\begin{tabular}{|l|l|l|}
\hline SISTEMA DE VANCOUVER & \multicolumn{1}{|c|}{ APA } & SISTEMA ELECTRÓNICO \\
\hline Privilegia obras & Privilegia autores & Privilegia enlaces \\
\hline Mensaje & Emisor & Receptor \\
\hline $\begin{array}{l}\text { Gentil con el lector al recogerse } \\
\text { en notas al pie de página, al fi- } \\
\text { nal de capítulo u obra }\end{array}$ & $\begin{array}{l}\text { Interrumpe lectura en el seno } \\
\text { de las obras, con apellidos }\end{array}$ & $\begin{array}{l}\text { Admite reacciones de usuarios en } \\
\text { pestañas interactivas }\end{array}$ \\
\hline $\begin{array}{l}\text { Proviene de sociedades médi- } \\
\text { cas inglesas }\end{array}$ & $\begin{array}{l}\text { No admite combinaciones con } \\
\text { el sistema anterior }\end{array}$ & Admite todo tipo de combinaciones \\
\hline $\begin{array}{l}\text { Sin conocimiento de estudio de } \\
\text { liquidación de uso }\end{array}$ & $\begin{array}{l}\text { Discusión en antropología so- } \\
\text { bre legitimidad de los etnógra- } \\
\text { fos, fue resuelta por alza de au- } \\
\text { toestima de autor por APA }\end{array}$ & $\begin{array}{l}\text { Teoría de receptores y poder del nú- } \\
\text { mero }\end{array}$ \\
\hline Flexible & Rígido & Hipertextual \\
\hline
\end{tabular}

Fuente: elaboración propia

Al APA, según su última edición, parece preocuparle más las formas de citar electrónicas que derrotar al sistema inglés; le interesa más el futuro que el pasado, porque se nota el esfuerzo de compatibilizar dentro de su oferta, los sistemas electrónicos, más cambiantes de suyo, inseguros y con pocas garantías de poseer una originalidad inusual en los archivos rediáticos. ${ }^{13} \mathrm{Y}$ con todo, más fecundos y con una altísima capacidad, muchas veces anónimas y/o seudónimas, de conectar unas ideas con otras y estas a su vez con millones más, a través de hipervínculos retroalimentarios. No sabría decirse si lo que el APA siente hacia los sistemas de referencias electrónicos es una amenaza que podría representar su sepultura, o una promesa que podría ser su nueva residencia como inquilino.

\section{Recomendación}

Citar no es un pecado. Es parte del oficio de un intelectual. De eso vivimos también muchos críticos, profesores y profesionales, de citar haciendo muchas veces refritos y en medio de eso, brindando alguna que otra idea original, acompañada de resultados empíricos y datos estadísticos al gusto, dándonos por bien pagados. Sólo los genios son los que hacen nuevas teorías que rompen con sus propios antecesores y eso es precisamente lo que los presenta a ellos ante la sociedad como tales.

Todas las universidades tienen derecho de adoptar el sistema de referencias que ellas estimen más eficaz y conveniente. Nadie discute ese derecho. El problema es que no se puede decir que un sistema sea superior a otro, hasta no contar con un dictamen de expertos que señalen las fallas de uno y las virtudes del otro. Es decir, no hay una resolución experticia que concluya que el sistema inglés no sirve para nada y el APA es superior. Como esto no existe, tenemos derecho a preguntarnos: ¿cómo se impuso el uno sobre el otro? Y, más aún, ¿hay justicia en penalizar desmesuradamente, en virtud de "vanidades de pequeñas diferencias", a estudiantes, doctorandos y maestrantes por no emplear la versión sexta que no mandata negrillas, propia de la versión cuarta, y que huelga en aquella el uso destacado de las obras en favor de apellidos? Sólo se puede denominar como una violencia epistémica, que se ha hecho pasar por científica, la imposición inconsulta de un sistema referencial sobre otro en las universidades, sean cuales sean. 
Aún cuando existan justificaciones legítimas de aceptar el APA, no se exime de presentar la historia y las causas de su recibimiento y la recomendación sana de despenalizar su uso y permitir un margen relativo de libertad y creatividad al usuario, de utilizar el sistema de referencias que más estime conveniente o combinarlos, siempre y cuando se guarde la coherencia y transparencia debidas.

En el espíritu de este ensayo ha dominado un sentido abierto y democrático, sin perjuicio de sus críticas y recomendaciones, siempre a favor de la excelencia de la enseñanza en nuestra Universidad, y sólo nos resta como cierre, llamar a la discusión académica de altura sobre las bondades y desventajas que representan todos los regímenes de cita que se emplean, y emplearon, en nuestra Alma Mater.

\section{Referencias bibliográficas}

APA http://www.cifcomlatinoamerica. com/Presentacion_Estilo_APA_6ta_ Edicion.pdf

Bauman, Zygmunt. La cultura como praxis. Paidós. Barcelona, 2002

--- Legisladores e intérpretes. Ed. Quilmes. Argentina, 1997

Eco, Umberto. Los límites de la interpretación. Ed. Lumen. Barcelona, 1992

Latour, Bruno. La Esperanza de Pandora. Gedisa. Barcelona, 2001

Nunca fuimos modernos. Siglo XXI. Bs. As. 2007

La prensa "Revista Domingo". Nicaragua. 2014

Sloterdijk, Peter. Ira y Tiempo. Estacao Libertade. Sao Paulo, 2012

Spivak, Gayatri. "¿Puede hablar el sujeto subalterno?" en Orbis Tertius. Año 3. No. 6. Universidad de La Plata. Argentina, 1998

Tyler, Stephen. "Acerca de la 'descripción/ desescritura' como un 'hablar por'. C. Geertz, J Cliffor et al. El surgimiento de la Antropología Postmoderna, Gedisa, Barcelona, 1991; págs: 289-294

Zizek, Slavoj. Viviendo el final de los tiempos. Akal. Madrid, 2010 